Collection: EFI 2008 Annual Conference Week - Orvieto (Italy) Adaptation of Forest Landscape to Environmental Changes Guest Editor: Giuseppe Scarascia Mugnozza (CRA - Rome, Italy)

\title{
Landscape genetics of fragmented forests: anticipating climate change by facilitating migration
}

\author{
Smulders MJM ${ }^{(1)}$, Cobben MMP ${ }^{(1)}$, Arens $P^{(1)}$, Verboom $J^{(2)}$ \\ Habitat fragmentation is a threat to the survival of species and causes popula- \\ tion decline, as isolated populations are more susceptible to demographic and \\ genetic stochasticity. This can be compensated for by sufficient spatial con- \\ nectivity between habitat patches to allow dispersal of individuals among po- \\ pulations. In that case such a network of populations may effectively form a \\ metapopulation. In this paper we discuss some aspects of metapopulation the- \\ ory, notably with respect to maintaining genetic diversity in fragmented forest \\ patches. In addition we will discuss recent studies that explore ways for forest \\ management to anticipate and mitigate the expected climate change, in rela- \\ tion to range shifts and colonisation opportunities.
}

Keywords: Genetic diversity, Management, Connectivity, Habitat fragmentation

\section{Metapopulations}

Levins $(1969,1970)$ introduced the term metapopulation as "a population of populations". The concept was developed for animal species (in fact, for pests on agricultural crops). A metapopulation consists of several distinct populations, each of which may go extinct. Migrants can re-colonise empty habitat patches. Migrants can also (demographically and genetically) rescue populations before they go extinct. Hence the network is stable in the long term, even though each individual population may not be. An essential characteristic of a metapopulation is therefore dispersal of individuals. A common characteristic is that some of the potentially suitable habitat is unoccupied at all times.

Although all aspects of a metapopulation (habitat patches which may or may not be occupied, dispersal and recolonisation) are

(1) Plant Research International, Wageningen UR, Wageningen, The Netherlands; (2) Alterra, Wageningen UR, Wageningen, The Netherlands

\section{@ MJM Smulders (rene.smulders@wur.nl)}

Received: Apr 08, 2009 - Accepted: Apr 09, 2009

Citation: Smulders MJM, Cobben MMP, Arens $P$, Verboom J, 2009. Landscape genetics of fragmented forests: anticipating climate change by facilitating migration. iForest 2 : 128-132 [online: 2009-07-30] URL:

http://www.sisef.it/iforest/show.php? id $=505$ also found in plant species, plants cannot easily disperse directionally. The majority of seeds and pollen may end up in the landscape matrix, without reaching suitable habitat. For that reason some people doubt whether plant species exhibit "true" metapopulation dynamics. Indeed, plant species have adaptations to cope with the dynamics of a metapopulation: longevity as an individual (to survive poor conditions, and to avoid loss of genetic diversity through overlapping generations), propagation as a clone, or the presence of a seed bank. It can be argued, however, that many plant species can deal very well with longer-distance dispersal and migration. They are pollinated by wind or by animals that are capable of moving directionally (insects, bats). Also for seed dispersal many different agents are engaged that can move directionally and bridge large distances (e.g., mammals, birds - Kramer et al. 2008a). So metapopulation theory may indeed be a meaningful concept for plant species in general and for forest species in particular.

The notion that networks of populations are more stable than isolated populations has become an important element in conservation policies. Next to protecting and enlarging existing natural areas, and improving their quality, the natural elements are now being connected by "corridors" of additional natural elements strategically placed between patches of natural habitat when they are deemed too far apart. Beier et al. (2008) discussed various choices and assumptions that arise when designing linkages to facilitate movement or gene flow of focal species between two or more natural areas. They recommend designing them for multiple focal animal species, as a "collective umbrella" for many species and ecological processes. When forest patches are connected with each other and with larger forest areas, animals living in the forest may move between these patches. It is anticipated that this will also enhance the movement of forest undergrowth plant species. In all cases the magnitude of the effect will be species-dependent.

\section{Population genetics in fragmented \\ forests}

Changing land use (e.g., conversion of forests to agricultural land) and logging have increased fragmentation and isolation of tree populations in many parts of the world (Geburek \& Konrad 2008). Many fragments are too small to sustain a viable population of a naturally regenerating tree species, and thus the amount of gene flow among the remnant populations and their level of genetic diversity are key factors that will ultimately determine the genetic consequences of habitat fragmentation (Aguilar et al. 2008). The effects of fragmentation on genetic diversity are then the result of population size, degree of isolation and matrix characteristics, and their interactions (Aguilar et al. 2008). Generally, one can expect that genetic diversity will be lost when gametes are exchanged is across larger distances and through more inhabitable areas.

Although forest fragmentation is widespread and locally very severe, one generally finds that the genetic diversity in mature trees in these fragments has not diminished (Aguilar et al. 2008). There are some exceptions, e.g., pasture trees that set less fruit compared to trees in a continuous forest, with a reduced number of parents (Rocha \& Aguilar 2001), and decreased diversity in fragmented populations of European beech in northeastern Spain (Jump \& Penuelas 2006), but this is not the general pattern. For this apparent paradox Kramer et al. (2008a) offered three possible causes, which may interact:

1. Pollination occurs across large distances. Many examples exist, but two will suffice to make the point. Fig wasps fly routinely several kilometres through tropical forest to find the next tree of the same species. Outside the forest they may cover many kilometers, but under those circumstances they may be considered wind-dispersed themselves. In the windpollinated European beech parentage studies showed that $44.6 \%$ and $71.8 \%$ of the seeds were pollinated from outside of the 
plot (Kramer et al. 2008b). Since pollination can occur across large distances, forest fragments that we consider to be separated may, in fact, form a continuous population for some of the tree species. Hence, we have to determine what delineates a "population" for the species under study (which is not necessarily an easy task - Waples \& Gaggiotti 2006). On the side, we may observe that the opposite may also be true as well: some tree species may be fragmented within a "continuous" forest if the species is sufficiently rare or suitable habitat is distributed very unevenly.

2. Not all seed dispersal is negatively affected by fragmentation. Forest fragmentation will affect populations of plants and animals if the fragment boundaries limit dispersal, so that the normal leptokurtic dispersal curve is limited at or near the outer edge of the forest fragment. This may be the case for seed dispersal by small arboreal, terrestrial, or weak-flying dispersal agents that do not cross open land. Other dispersal curves may not be affected at all. Quite the opposite ("fat" dispersal curves) may in fact be common for seeds dispersed by large birds, large bats, and terrestrial birds or mammals, since these are forced to move further than they otherwise would to reach the next suitable forest patch (directed dispersal).

3. The effect of generation time. Population genetic theory predicts that small populations have less diversity, provided that they have had sufficient time to experience genetic drift, inbreeding, and ultimately inbreeding depression. However, stands in fragments are mostly living relicts of predisturbance populations of largely unrelated individuals. In general it is accepted that after habitat fragmentation the effects on genetic diversity have a lag time that is related to the generation time of the focal organism (Honnay et al. 2005). It can easily take several generations of isolation before clear effects become apparent.

This genetic "lag time" may have led Kramer et al. (2008a) to state that genetic degradation may not be as important as ecological degradation for many decades following habitat fragmentation. However, when Lowe et al. (2005) reviewed studies of several neotropical tree species, they found mostly no effect on genetic diversity, but they did observe that progeny inbreeding, reproductive output, and fitness were impacted. This pattern would be expected if the parents are derived from large populations, but their mating is limited, and their current offspring is therefore derived from a limited number of parental trees. Also Aguilar et al. (2008) warned for shifts in mating patterns towards increased selfing. Sork \& Smouse (2006) mentioned the example of pollen in savannah populations of Quercus lobata, which moved larger distances but at the same time the seedlings resulted from a smaller number of pollen donors compared to forest populations of Quercus alba. Studies of black poplar (Populus nigra) in the Netherlands and other European countries have uncovered two other processes. The mature poplar trees along the Rhine river are largely pure $P$. nigra, but the populations consist of only a few genotypes as the trees show increased levels of clonal propagation as a result of reduced river dynamics (Arens et al. 1998, Smulders et al. 2008a). In addition, when Smulders et al. (2008b) studied the seedlings along the shores of the Rhine river they found that almost $50 \%$ of the seedlings were offspring of crosses with hybrid P. $x$ canadensis cultivars, which have been planted in large numbers on cultivated fields and along roads. The reduction of the population size of naturally occurring trees compared to the number of planted hybrid cultivars thus leads to alterations in the genetic composition of the offspring, which may affect future generations of this species.

A final process that we may mention is the change in management in many European forests, which generally involved a decrease of human management activity with the aim to mimic more 'natural' processes. This has resulted in a strong decrease of available germination sites for many forest plant species (Arens et al. 2005, Jacquemyn et al. 2008, Jacquemyn et al. 2009).

Aguilar et al. (2008) performed a metaanalysis on isoenzyme studies of fragmented plant populations. The effects of 50 years fragmentation on number of alleles, number of polymorphic loci, and expected heterozygosity were not yet statistically significant (they were after 100 years). Clearly the effects for tree species may be even more difficult to detect, as they are long-lived and have largely overlapping generations. Aguilar et al. (2008) concluded that conservation efforts in fragmented habitats should be focused on common species or species that recently became threatened, and on mainly outcrossing species, as these will suffer the most from fragmentation. Honnay \& Jacquemyn (2007) came to a similar conclusion.

\section{Climate change}

Climate change is changing habitat conditions, leading to (more or less predictable) shifts in optimal habitat conditions with increased latitude and altitude. Furthermore, yearly weather variability will increase. Many species have been observed to expand their range northward and upward, including insects (Battisti 2008). Climate change is caused by a steady increase in greenhouse gasses, notably $\mathrm{CO}_{2}$, but how plants will react to the combination of these two processes is, at best, unclear.

The temperature gradient from north to south along the European Atlantic coast is about $0.005{ }^{\circ} \mathrm{C}$ per $\mathrm{km}$. A predicted change of $4{ }^{\circ} \mathrm{C}$ in 100 years therefore means that each temperature isocline will move $800 \mathrm{~km}$, i.e., travel with a speed of on average $8 \mathrm{~km}$ per year across flat land (changes take place across smaller distances when going uphill in mountainous regions). How does such a potential increase of temperature affect tree species distribution? To survive, a species can either shift its range or adapt to the changing conditions, or both. Palynological and historical data on the speed at which tree species move indicate that tree movement is highly species-dependent, but in the range of 0.25-1.5 km per year (Kräuchi 1993, Savolainen et al. 2007b), the largest value being for conifers. Kremer (2007) estimated that, at maximum, trees would be able to shift their range $10-70 \mathrm{~km}$ during the coming hundred years, not taking into account habitat fragmentation. These estimates do not take into account rare long distance dispersal event, as these are very difficult to measure, and therefore it is also difficult to quantify their possible impact. It is thought that long distance dispersal may have played a large role in the recolonisation of Europe that followed the last ice age. Real movement of Norway spruce $(6 \mathrm{~km}$ to the North in the 60 years period from 1935 to 1995 - Savolainen et al. 2007a) is in accordance with the models.

Forest tree species show clines of adaptive traits, in spite of a high level of gene flow in large continuous populations. Savolainen et al. (2007a) argued that selection in tree populations can be strong because mortality is high, especially in the seedling stage. Hence, there is considerable capacity for high selection differentials. In addition, the populations may be large and continuous but the habitat is heterogeneous. On the downside, as mature trees are long-lived, they will spread their genes, which mostly reflect selection at the seedling stage, for a very long time. Indeed, when they modelled Norway spruce populations under climate change, adult trees that had become mal-adapted but did not die due to frost damage or competition actually slowed down the adaptive response of the populations. Even when they stopped climate change in the model, the populations took 500 years to fully adapt genotypically and phenotypically. Pollen migration from the south could increase the rate of adaptation.

We should distinguish between the processes that will take place at the front (the leading edge) of the species distribution, where conditions are generally improving as a result of global warming and the species can therefore potentially expand its range, and the rear (lagging) edge of the distribution, where conditions for species survival are worsening (Mátyás 2007, Manning et al. 
2009).

At the front, where the tree species distribution is generally limited by temperature the conditions are slowly improving, and new patches of habitat become available. However, colonization is hampered by the fact that, as existing populations are still marginal, there are only few dispersers. In addition, these may have problems in dispersing into the new habitat across inhabitable landscape. Forest trees have an extra problem, as the right conditions for seedling survival and establishment may occur only once every several decades (Kräuchi 1993) Once a new population is formed, it initially is small and relatively isolated from the centre of the distribution of the species. This means that genetic drift in this population can be quite high, leading to loss of genetic diversity. Next to this, genetic diversity can be lost by adaptation to local conditions. Deleterious mutations have a significantly larger chance of establishing themselves in these small populations (Burton \& Travis 2008). A solution could be to increase existing habitat to enlarge populations, as large populations generate more migrants (Schippers et al. 2009), and to enhance the movement of migrant seeds by constructing nature corridors. This will also reduce the occurrence of genetic drift.

At the rear edge of the species distribution the habitat quality is dropping below the lower limit, and the species will disappear a that location unless it is able to adapt to the new conditions. Actual extinction may, however, take a long time to occur, a period during which the species has an "extinction debt". Hence, existing forests may survive for a long time after conditions suitable for germination and establishment have disappeared. During that time they will still produce seeds, and since the yearly weather variability is much larger than the gradual increase in average temperature due to climate change, there may still be years in which seedlings can establish themselves. However, this period may end very abruptly with a mortality wave due to extreme weather conditions. This will probably be a year with extreme drought, as drought stress is the most important factor at the southern limit of the distribution of many tree species (Mátyás 2007).

\section{Climate change and fragmented forests}

So we see that tree species will have great difficulty achieving the speed of range shift that is necessary to follow their habitat. If, next to this, movement of propagules poleward, and up hill, is also limited by habitat fragmentation, extinction rates will increase This means that adaptation to climate change becomes an important survival option. As Savolainen et al. (2007b) stated, much more research is required on adaptation to climate change. We would like to present some measures that forest managers might take, mainly to mitigate the effects of habitat fragmentation. The measures can help the adaptation of the cultivated tree species, the adjustment of the composition of tree species in a forest, or both. When applying these measures the whole forest ecosystem must be considered.

A stable metapopulation consists of three elements: occupied source patches that produce propagules, empty or nearly empty patches that receive propagules, and dispersal from one patch to the other.

With regard to source patches, forest reserves as we know them may not be a suitable way to conserve genetic diversity for the future, as in a dynamic world the conditions at the site will change. So even for forest reserves aimed at maintaining diversity rather than using it, we have to act. One possible measure is to take a large sample of the seedlings and transfer them to one or more other locations which are expected to be suitable in the (near) future, and thus to establish new sites for in situ conservation and use. This facilitation of range shifts for tree species is a form of "anticipatory forestry" (as a variation of Manning's phrase "anticipatory restoration" - Manning et al. 2009). Kremer (2007) mentions several historical examples where seed of natural and exotic forest trees have been transferred in many different directions in Europe, and argues that the adaptations of the populations derived from these transfers clearly suggest that evolutionary rates might be quite substantial, despite the long generation intervals of trees. St. Clair \& Howe (2008) propose to mix local populations of Douglas fir with a proportion of trees from lower elevations and further south. This would increase the frequency of alleles that may be selected for as a result of climate change.

As for empty patches for the cultivated tree species, the management system used by the foresters determines the magnitude and geographical distribution of reforestation. This provides a good opportunity to anticipate at least some of the negative effects of climate change and fragmentation we mentioned. Lindgren (2008) advocated anticipating temperature change in tree breeding in Sweden by widening the range of testing sites for a breeding population to about $0.5-1$ degrees of latitude. Deploying genetic materials at 50 $m$ higher elevation than at which it is currently generated and selected would accommodate about $0.5 \mathrm{C}$ degree warming during the lifespan of the trees. Lindgren (2008) considered these changes "safe", as they are unlikely to over-compensate for global warming. Given the latest IPCC reports on the predicted temperature increase a much larger change may be warranted, up to $1-2$ degree $\mathrm{C}$ warming. Indeed, St. Clair \& Howe (2008) expect that Douglas fir populations in the US a century from now should be adapted to climates from locations that are currently 450-1130 $\mathrm{m}$ lower in elevation and 1.8-4.9 degrees more southern in latitude.

Translocation experiments (described by Savolainen et al. 2007b) have shown that tree species typically can grow to $80 \%$ of their maximum height when transplanted to a location that is not optimal at the moment but is anticipated to have suitable climate conditions in the future, without major yield losses. This means that seedlings may be transferred to a location that is anticipated to be optimal without major yield losses. The actual yield loss would be expected to decrease to zero as a result of the progress of climate change. Note that this applies both for different provenances from one species and for tree species that do not yet occur in the forest.

Kramer et al. (2008b) modelled beech forests with different management regimes. They showed that increased management intensity, which leads to more frequent regeneration, allows the species to adapt significantly faster, as selection takes place in the seedling and sapling stage. This strategy would apply to forest reserves as well, as a "no management" strategy may prove to be a "dead end".

With regard to dispersal, a species that has a continuous distribution across contrasting ecological sites might be able to "import" genes contributing to higher fitness in areas exposed to severe stress (Kremer 2007). If the distribution is scattered and disrupted this dispersal is less likely. A clear albeit rather specific case exists when habitat is naturally disjoint, such as in the case of mountain slopes. When trees move up the mountain slope they have to adapt on each mountain. It can be envisaged that it may be useful to move adapted seedlings from one mountain slope to comparable habitat sites on another mountain slope, if those sites contain small populations.

As deciduous and coniferous trees move to higher latitude and altitude deciduous trees will invade today's subalpine belt, displacing various conifers (Kräuchi \& Kienast 1993). Lindner (2007) discussed some management options at the level of the forest type and composition: we can move towards mixed species forests with varying ecological characteristics, we can diversify forest types, and we can gradually replace the major forest species. He furthermore argued for diversifying adaptation strategies as this leaves more options under uncertain future conditions. This could be done by having seed orchards at various latitudinal and altitudinal locations, with a maximum of different lines to produce the reproductive material for forest regeneration (Mátyás 1996). 
Up to now we only discussed here possible strategies for the forest tree species, and then especially those managed for production. Some of our management activities would be applicable for forests with natural regeneration as well. However, next to tree species, also all other species present in the forest ecosystem (plants of the forest undergrowth, animals, soil biota) will need to adapt locally, and/or to move when their suitable climate moves. Decreasing fragmentation of natural areas is common policy in nature conservation. This can be done by enlarging current natural areas, by connecting them, or by a combination of these two types of measures. Corridors are typically designed for use by a limited number of (large) mammals (Beier et al. 2008), but they are used by many other (smaller) animal species as well, and through these they also may assist in dispersal of plant species. For instance, Grashof-Bokdam et al. (2009) found that the occurrence of typical woodland bird, butterfly, and herb species was correlated with the existence of a network of forest patches and corridors. Connecting forests is the only measure that would help all non-tree species in the forest to shift their ranges in response to climate change. This may be especially true for the reserves, which contain valuable genetic sources for a range of species of the forest ecosystem. It will be especially effective if combined with a management regime that creates sufficient windows of opportunity for colonisation and for rejuvenation of populations.

\section{Acknowledgements}

Research by the authors is supported by the Netherlands' Ministry of Agriculture, Nature Conservation and Food Quality through its strategic research program: "Sustainable spatial development of ecosystems, landscapes, seas and regions" (projects KB-01-007-001PRI and KB-01-007-013-PRI), by the Dutch National Research Programme Climate changes Spatial Planning (http://www.klimaatvoorruimte.nl/), and by the Commission of the European Community, Network of Excellence Evoltree, contract no. 016322, under the $6^{\text {th }}$ Framework Programme, priority 6: "Sustainable development, Global Change and Ecosystems". It does not necessarily reflect its views and in no way anticipates the Commission's future policy in this area.

\section{References}

Aguilar R, Quesada M, Ashworth L, HerreriasDiego Y, Lobo J (2008). Genetic consequences of habitat fragmentation in plant populations: susceptible signals in plant traits and methodological approaches. Molecular Ecology 17: $5177-$ 5188. - doi: 10.1111/j.1365-294X.2008.03971.x Arens P, Coops H, Jansen J, Vosman B (1998). Molecular genetic analysis of black poplar ( $\mathrm{PO}-$ pulus nigra L.) along Dutch rivers. Molecular Ecology 7: 11-18. - doi: 10.1046/j.1365294x.1998.00316.x

Arens P, Bijlsma RJ, van't Westende W, van Os B, Smulders MJM, Vosman B (2005). Genetic structure in populations of an ancient woodland sedge, Carex sylvatica Hudson, at a regional and local scale. Plant Biology 7: 387-396. - doi: 10.1055/s-2005-865644

Battisti A (2008). Forests and climate change lessons from insects. iForest 1: 1-5 - doi: 10.3832/ifor0210-0010001

Beier P, Majka DR, Spencer WD (2008). Forks in the road: choices in procedures for designing wildland linkages. Conservation Biology 22: 836-851. - doi: 10.1111/j.1523-1739.2008. 00942.x

Burton OJ, Travis JMJ (2008). Landscape structure and boundary effects determine the fate of mutations occurring during range expansions. Heredity 101: 329-340. - doi: 10.1038/hdy.2008. 56

Geburek T, Konrad H (2008). Why the conservation of forest genetic resources has not worked. Conservation Biology 22: 267-274. - doi: 10.1111/j.1523-1739.2008.00900.x

Grashof-Bokdam CJ, Chardon JP, Vos CC, Foppen RPB, WallisDeVries $M$, van der Veen $M$, Meeuwsen HAM (2009). The synergistic effect of combining woodlands and green veining for biodiversity. Landscape Ecology - doi: 10.1007/ s10980-008-9274-z

Honnay O, Jacquemyn H (2007). Susceptibility of common and rare plant species to the genetic consequences of habitat fragmentation. Conservation Biology 21: 823-831. - doi: 10.1111/ j.1523-1739.2006.00646.x

Honnay O, Jacquemyn H, Bossuyt B, Hermy M (2005). Forest fragmentation effects on patch occupancy and population viability of herbaceous plant species. New Phytologist 166: 723-736 doi: 10.1111/j.1469-8137.2005.01352.x

Jacquemyn H, Brys R, Honnay O, Hermy M (2008). Effects of coppicing on demographic structure, fruit and seed set in Orchis mascula. Basic and Applied Ecology 9: 392-400. - doi: 10.1016/j.baae.2007.05.002

Jacquemyn H, Brys R, Adriaens D, Honnay O, RoldaÌn-Ruiz I (2009). Effects of population size and forest management on genetic diversity and structure of the tuberous orchid Orchis mascula. Conservation Genetics 10: 161-168. - doi: 10.1007/s10592-008-9543-Z

Jump AS, Penuelas J (2006). Genetic effects of chronic habitat fragmentation. Proceedings of the National Academy of Sciences USA 103 (21): 8096-8100. - doi: 10.1073/pnas.0510127103

Kramer AT, Ison JL, Ashley MV, Howe HF (2008a). The paradox of forest fragmentation genetics. Conservation Biology 22: 878-885. - doi: 10.1111/j.1523-1739.2008.00944.x

Kramer K, Buiteveld J, Forstreuter M, Geburek T, Leonardi S, Menozzi P, Povillon F, Schelhaas MJ, Teissier du Cros E, Vendramin GG, van der Werf DC (2008b). Bridging the gap between ecophysiological and genetic knowledge to as- sess the adaptive potential of European beech. Ecological Modelling 216: 333-353. - doi: 10.1016/j.ecolmodel.2008.05.004

Kremer A (2007). How well can existing forests withstand climate change? In: "Climate change and forest genetic diversity: Implications for sustainable forest management in Europe" (Koskela, J, Buck, A, Teissier du Cros E eds). Bioversity International, Rome, Italy, pp. 3-17.

Kräuchi N (1993). Potential impacts of a climate change o forest ecosystems. European Journal of Forest Pathology 23: 28-50. - doi: 10.1111/j. 1439-0329.1993.tb00804.x

Kräuchi N, Kienast F (1993). Modelling subalpine forest dynamics as influenced by a changing environment. Water, Air, and Soil Pollution 68: 185-197. - doi: 10.1007/BF00479402

Levins R (1969). Some demographic and genetic consequences of environmental heterogeneity for biological control. Bulletin of the Entomological Society of America 15: 237-240.

Levins R (1970). Extinction. In: "some mathematical problems in biology" (Gesternhaber M ed.). American Mathematical Society, Providence, Rhode Island, USA, pp. 77-107.

Lindgren D (2008). Immediate genetic changes in tree deployment and breeding because of global warming. In: "International conference on adaptation of forests and forest management to changing climate with emphasis on forest health: a review of science, policies and practices". Umea (Sweden) 25-28 August, 2008. Book of Abstracts and Preliminary Programme, pp. 147. [online] URL: http://www.fao.org/forestry/foris/pdf/adaptation/ book of abstracts.pdf

Lindner M (2007). How to adapt forest management in response to the challenges of climate change? In: "Climate change and forest genetic diversity: implications for sustainable forest management in Europe" (Koskela J, Buck A, Teissier du Cros E eds). Bioversity International, Rome, Italy. pp. 31-42.

Lowe AJ, Boshier D, Ward M, Bacles CFE, Navarro $C$ (2005). Genetic resource impacts of habitat loss and degradation; reconciling empirical evidence and predicted theory for neotropical trees. Heredity 95: 255-273. - doi: 10.1038/sj. hdy. 6800725

Manning AD, Fischer J, Felton A, Newell B, Steffen W, Lindenmayer DB (2009). Landscape fluidity - a unifying perspective for understanding and adapting to global change. Journal of Biogeography 36:193-199. - doi: 10.1111/j.13652699.2008.02026.x

Mátyás C (1996). Climatic adaptation of trees: rediscovering provenance tests. Euphytica 92: 45 54. - doi: 10.1007/BF00022827

Mátyás C (2007). What do field trials tell about the future use of forest reproductive material? In: "Climate change and forest genetic diversity: implications for sustainable forest management in Europe" (Koskela J, Buck A, Teissier du Cros E eds). Bioversity International, Rome, Italy, pp.53-69.

Rocha OJ, Aguilar G (2001). Reproductive biology of the dry forest tree Enterolobium cyclo- 
carpum (guanacaste) in Costa Rica: a comparison between trees left in pastures and trees in continuous forest. American Journal of Botany 88: 1607-1614. [online] URL: http://www.amjbot. org /cgi/content/abstract/88/9/1607

Savolainen O, Bokma F, Knürr T, Kärkkäinen K, Pyhäjärvi T, Wachowiak W (2007a). Adaptation of forest trees to climate change. In: "Climate change and forest genetic diversity: implications for sustainable forest management in Europe" (Koskela J, Buck A, Teissier du Cros E eds). Bioversity International, Rome, Italy, pp. 19-30. [online] URL: http://www.bioversityinternational.org/networks/euforgen/workshop/Presentations/Savolainen.pdf

Savolainen O, Pyhäjärvi T, Knürr T (2007b). Gene flow and local adaptation in trees. Annual Review of Ecology, Evolution and Systematics 38: 595-619. - doi: 10.1146/annurev.ecolsys.38 091206.095646

Schippers P, Vos CC, Verboom J, Jochem R
(2009). Metapopulation dynamics under climate change: will species be able to track? (submitted).

Smulders MJM, Cottrell JE, Lefèvre F, van der Schoot J, Arens P, Vosman B, Tabbener HE, Grassi F, Fossati T, Castiglione S, Krystufek V, Fluch S, Burg K, Vornam B, Pohl A, Gebhardt K, Alba N, Agúndez D, Maestro C, Notivol E, Volosyanchuk R, Pospíšková $\mathrm{M}$, Bordács $\mathrm{S}$, Bovenschen J, van Dam BC, Koelewijn HP, Halfmaerten D, Ivens B, van Slycken J, Vanden A, Broeck, Storme V, Boerjan W (2008a). Structure of the genetic diversity in Black poplar (Populus nigra L.) populations across European river systems: consequences for conservation and restoration. Forest Ecology and Management 255: 1388-1399. - doi: 10.1016/j.foreco.2007. 10.063

Smulders MJM, Beringen R, Volosyanchuk R, Vanden Broeck A, van der Schoot J, Arens P, Vosman B (2008b). Natural hybridization between Populus nigra L. and P. $x$ canadensis Moench. Hybrid offspring competes for niches along the Rhine river in the Netherlands. Tree Genetics and Genomes 4: 663-675. - doi: 10.1007/s11295-008-0141-5

Sork VL, Smouse PE (2006). Genetic analysis of landscape connectivity in tree populations. Landscape Ecology 21: 821-836. - doi: 10.1007 /s10980-005-5415-9

St. Clair JB, Howe GT (2008). Genetic maladaptation of coastal Douglas-fir seedlings to future climates. Global Change Biology 13: 1441-1454. doi: 10.1111/j.1365-2486.2007.01385.x

Waples RS, Gaggiotti O (2006). What is a population? An empirical evaluation of some genetic methods for identifying the number of gene pools and their degree of connectivity. Molecular Eco$\operatorname{logy} 15$ : 1419-1439. - doi: 10.1111/j.1365294X.2006.02890.x 